\title{
O Sujeito na Epistemologia Lacaniana e sua Implicação para os Estudos Organizacionais
}

\author{
The Subject in Lacanian Epistemology and its Implication for Organizational Studies \\ Ketlle Duarte Paes ${ }^{1}$ \\ Universidade Federal de Santa Catarina / Programa de Pós-Graduação em Administração, Florianópolis - SC, Brasil \\ Eloise Helena Livramento Dellagnelo ${ }^{2}$ \\ Universidade Federal de Santa Catarina / Centro Sócio-Econômico, Florianópolis - SC, Brasil
}

\section{Resumo}

Este artigo discute a problemática do sujeito no âmbito do movimento pós-estruturalista, sobretudo na epistemologia lacaniana, e seu rompimento com a visão tradicional do sujeito na modernidade, refletindo sobre sua influência nas teorias organizacionais. O sujeito moderno é o sujeito do cogito cartesiano, pleno e autoconsciente. Os apontamentos de Nietzsche e, sobretudo, de Lacan desconstroem os traços essencialistas do sujeito cartesiano para pôr em seu lugar um sujeito que se constitui na e pela linguagem. Essa qualidade ontológica do ser não permite seu fechamento em uma identidade fixa. Em Lacan, o sujeito é sempre falta-a-ser, que se move de identificação em identificação, em uma contingência necessária e estruturante.

Palavra-chave: Estudos organizacionais. Epistemologia. Psicanálise. Sujeito.

\section{Abstract}

This article discusses the subject's issue within the post-structuralist movement, above all in Lacanian epistemology, and its break with the traditional view on the subject in modernity, thinking through its influence on organizational theories. The modern subject is the Cartesian cogito's subject, full and self-conscious. The notes by Nietzsche and, above all, Lacan deconstruct the Cartesian subject's essentialist traits to replace it by a subject who is constituted in and through language. This ontological quality of being does not allow its closure in a fixed identity. According to Lacan, the subject is always lack-to-be, who moves from identification to identification, in a necessary and structuring contingency.

Keywords: Organizational studies. Epistemology. Psychoanalysis. Subject.

Artigo submetido em 31 de janeiro de 2014 e aceito para publicação em 24 de novembro de 2014.

\section{DOI: http://dx.doi.org/10.1590/1679-395115872}

${ }^{1}$ Doutoranda do Curso de Pós-Graduação em Administração (CPGA) - Universidade Federal de Santa Catarina (UFSC). Endereço: UFSC, Campus Trindade, Centro Socioeconômico - sala 224 - CEP 88040-900, Florianópolis - SC, Brasil. E-mail: ketllep@yahoo.com.br

${ }^{2}$ Doutora em Engenharia de Produção - EGP/Universidade Federal de Santa Catarina (UFSC); Professora Associada da Universidade Federal de Santa Catarina. Endereço: UFSC, Campus Trindade, Centro Socioeconômico - sala 227 - CEP 88040-900, Florianópolis - SC, Brasil. E-mail: eloise@cse.ufsc.br 


\section{Introdução}

O campo das ciências humanas emerge com o a modernidade, período no qual o homem ganha centralidade como sujeito de conhecimento. Foucault (1999), em As palavras e as coisas, faz uma arqueologia das ciências humanas e mostra que na modernidade houve uma mudança na forma de pensar o mundo e o homem. Assim, o homem, visto como sujeito, é um problema recente para os saberes filosóficos e científicos, com origem nos séculos XVIII e XIX, em razão, principalmente, das reflexões kantianas sobre nossa capacidade de conhecer (FOUCAULT, 1999).

Também Machado (2007) expõe que as reflexões foucaultianas são inspiradas no legado de Nietzsche, para quem, a história da filosofia ocidental é uma ficção que nega a vida. Uma ilusão sob a qual se construiu uma concepção de homem que não existe e nunca existirá, já que essa imagem é arquetípica de um homem autoconsciente, racional e pleno. Esse modelo de homem, em termos epistemológicos, nasce com Descartes em suas reflexões sobre ser e pensamento, o que conduz à dualidade corpo e alma. O homem (sujeito) da filosofia cartesiana é imortal e único, é uma entidade metafísica que pensa e que conhece, é, portanto, o fundamento de todo o conhecimento (DOSSE, 2007).

Essa noção de sujeito foi apropriada e refinada pelas correntes do pensamento filosófico ocidental que se sucederam desde Descartes até Hegel, servindo, assim, de base para a epistemologia em ciências sociais em geral e em ciências da administração em particular. Quem rompe com essa tradição intelectual e lança as bases para o chamado pensamento pós-estruturalista e, consequentemente, para outra concepção de sujeito é Friedrich Nietzsche (1844-1900). Com sua filosofia acidamente anti-humanista, este filósofo alemão defende outra perspectiva para a compreensão do mundo. Longe do pensamento da dialética e da identidade, Nietzsche defende o jogo da diferença como constituinte da realidade social.

Para Foucault (1999), a pergunta kantiana o que é o homem é a mais embaraçosa já feita na modernidade. Essa pergunta suscita uma disputa em torno da definição de homem, dividindo o campo científico em duas vertentes epistemológicas principais, o objetivismo e o subjetivismo. No objetivismo, o sujeito é excluído da relação de conhecimento. Conforme essa corrente, o conhecimento está no objeto e é externo ao sujeito. Uma variante dessa epistemologia é o estruturalismo, para o qual o sujeito não passa de um apêndice estrutural; a ênfase é dada à estrutura e não à ação (HESSEN, 2003; BOURDIEU, 2011).

Já no subjetivismo predomina a ação. Para essa corrente epistemológica o sujeito é responsável e autoconsciente de suas ações no mundo, constituindo-se em um sujeito racional e autônomo. De acordo com essa corrente, o conhecimento não pertence mais ao objeto, mas sim à subjetividade do sujeito. Uma variante dessa epistemologia é a fenomenologia, cujo objeto é captar a experiência primeira do mundo social tal como cotidianamente vivida pelos sujeitos (HESSEN, 2003; BOURDIEU, 2011).

Essa discussão (objetivismo/subjetivismo), tão importante nas ciências humanas, acaba por se refletir em suas disciplinas especializadas, como a ciência da administração. A importância de se fazer essa reflexão, que passa necessariamente pela problemática do sujeito, está em desconstruir os falsos dualismos e, portanto, questionar o reducionismo que advém das polarizações que abrigam questões como teoria/prática, sujeito/objeto, ação/estrutura (BOURDIEU, 2011; CLEGG e HARDY, 2001; PAULA, 2008; 2012).

A polarização entre as perspectivas objetivista e subjetivista também se observa em Estudos Organizacionais (CLEGG e HARDY, 2001; PECI, 2003). Vergara e Caldas (2005) observam que até a década de 70, predominava a abordagem objetivista na área, após essa data os estudos interpretacionistas crescem, bem como os estudos críticos e as perspectivas pós-estruturalistas e psicanalíticas. Peci (2003) e Paula (2008) observam que nas ciências sociais, principal matriz das apropriações da área de organizações, há em algumas abordagens uma preocupação em solapar a dicotomia objetivismo/subjetivismo, tais como as perspectivas teóricas de Pierre Bourdieu e Antony Giddens. 
Entretanto, na visão de Paula (2008), essas abordagens só parcialmente cumprem esse propósito. Para a autora, embora haja um claro esforço desses pensadores em romper com os dualismos, suas abordagens pendem mais para o objetivismo, o que reduz a importância do sujeito na construção da realidade. Por se coadunar com a superação das falsas dicotomias, este ensaio tem como proposta uma reflexão sobre a noção de sujeito no âmbito do movimento pós-estruturalista, sobretudo na epistemologia lacaniana, e seu rompimento com a visão tradicional do sujeito na modernidade, que tem influência também sobre os estudos organizacionais. A ideia de sujeito em Lacan rompe com as falsas dicotomias na medida em que o sujeito é entendido como imerso em sua relação dialética (sem a síntese) com a linguagem (estrutura), emergindo desse encontro um sujeito em falta, movido por afetos inconscientes.

Sobre a interface entre a psicanálise e os estudos organizacionais, é possível encontrar uma série de autores que se lançaram a esse desafio: Motta (2000), Paula (2012; 2013), Freitas (2007), Godói (2007), Sant'Anna (2011), Guimarães e Filho (2012), Paes e Dellagnelo (2013). Para Freitas (2007), a ampliação das fronteiras disciplinares representa uma forma de reduzir o narcisismo teórico e acadêmico, além de proporcionar outra visão sobre o sujeito, que, longe de ser autônomo e autoconsciente, é constituído por forças sociais e libidinais.

Para tanto, na primeira parte do presente estudo, serão abordadas as concepções de homem na modernidade e em seguida apresentado o sujeito lacaniano. O terceiro tópico trata das concepções de homem dentro do pensamento tradicional da administração e o ponto de inflexão que representou a abordagem crítica nessa temática. Por fim, uma reflexão comparativa entre as abordagens modernistas de homem (pleno, autoconsciente) e sujeito lacaniano (sujeito em falta constitutiva).

Neste trabalho busca-se contribuir com as discussões acerca de novas lentes de análise para a área de Estudos Organizacionais, sobretudo, no que diz respeito à noção de homem empregada na teoria administrativa. Isso porque, conforme analisam Souza, Souza e Silva (2013), as pesquisas organizacionais realizadas no campo subjetivo baseiam-se, em sua maioria, na ideia de que o homem possui um conhecimento absoluto de si e do mundo e de que seu discurso necessita ser interpretado, para que se consiga retirar, descobrir, analisar e entender o seu verdadeiro significado. Dito isso, menciona-se desde já que a noção de sujeito emersa com o pós-estruturalismo rompe com essa visão racionalista do sujeito.

A reflexão sobre a ideia de homem predominante em Estudos Organizacionais é importante para se pensar as implicações que as ferramentas de gestão impõem aos sujeitos. Conforme já apontaram Ramos (1984), Chanlat (2000), Faria e Meneguetti (2007), Paula (2012), entre outros, o modelo hegemônico de organização, pautado em uma ideia reducionista de homem, impõe a unidimensionalização da vida do sujeito na medida em que o reduz a uma criatura que se comporta e responde a estímulos.

Conforme Ramos (1984), as características psicológicas imputadas ao homem pela teoria dominante em organizações implicam algumas consequências aos modelos de organização cujas técnicas e ferramentas de gestão são uma evidência disso. De acordo com Faria e Meneguetti (2007), as ferramentas do management estão imersas na ideologia capitalista. Fato que leva, segundo os autores, ao sequestro da subjetividade, visto que as organizações incutem nos sujeitos seus objetivos e valores de forma que internalizem o próprio controle.

\section{Concepções de Sujeito na Modernidade: da Filosofia da Consciência ao (Pós)estruturalismo}

A problemática do sujeito é recente na tradição filosófica ocidental, tendo, pois sua origem no mundo moderno. Os antigos gregos estavam mais interessados em especular sobre os problemas da natureza e, por isso, buscavam uma explicação racional e sistemática do universo. Em virtude disso, desenvolveram várias formas de conhecimento, tais como a física, a matemática, a astronomia e a lógica. 
Contudo, se a preocupação dos antigos era desvendar a origem e as transformações da natureza, o problema que se impôs à filosofia moderna ocidental foi o de indagar sobre o conhecimento e, portanto sobre o sujeito. É com a modernidade que valores como racionalismo, humanismo e liberdade tornam-se essenciais e a razão torna-se o centro do conhecimento (FOUCAULT, 1999).

Nietzsche (2006) observa que a história do pensamento ocidental configura-se como uma busca por um fundamento, por uma explicação sobre as coisas do mundo. O pensamento ocidental, desde Sócrates, Platão e Aristóteles até os filósofos modernos Kant e Hegel, foi a história de uma ilusão que produziu a crença na identidade, na essência do ser e na verdade. Esta crença é o produto da necessidade humana de duração e apoia o anseio metafísico por um fundamento sobre as coisas.

Embora Nietsche (2006) não acreditasse nos ideais iluministas de progresso humano, nem na relação causa/efeito, nem que a história seja uma sequência de fatos em evolução, esses são valores por excelência do mundo moderno e, portanto, as bases sobre as quais se assentam o conhecimento sobre o homem.

Para Nietzsche (2006), a história da filosofia moderna configura-se na cristalização da ideia de substância. Assim, o que sustenta a busca pelo conhecimento é a crença de que existe uma verdade irredutível a ser alcançada. Entretanto, o autor adverte que a existência de uma essência do mundo é uma ficção, já que no mundo, ao contrário da unidade/identidade, impera a multiplicidade, impera o devir.

Conforme assinala Mosé (2011), a crítica da ideia de sujeito é central no pensamento crítico nietzschiano, uma vez que é a crença de que somos sujeito, de que somos unidade e, sobretudo, de que somos a origem do conhecimento e os depositários da razão, que permite a produção do mundo como substância, como essência, como unidade e como universalidade. Dito isso, Mosé (2011, p. 169) afirma que a essencialidade do sujeito não é, para Nietzsche, "[...] mais uma ficção que adquiriu valor de verdade; ao contrário, é a crença no sujeito pleno que permite a substancialização da realidade".

Nietzsche, em A gaia ciência, revela que a ideia do homem como medida de todas as coisas é um empreendimento moderno. Assim, a metafísica moderna que impõe um conhecimento sobre o mundo com base em regularidades estáveis e de unidades de sentido só foi possível por meio da produção da ideia de sujeito. Na visão de Nietzsche, extraímos a noção de unidade do nosso conceito do "eu", uma interioridade ativa, autônoma e causa das coisas (efeitos).

Essa crítica de Nietzsche, retomada depois pelos chamados filósofos pós-estruturalistas, é dirigida à filosofia da consciência/sujeito, inspirada, sobretudo, no pensamento cartesiano/kantiano. Assim, em termos epistemológicos, o sujeito moderno nasce das reflexões de Descartes e se consolida como sujeito do conhecimento com Kant (FOUCAULT, 1999). Para o cartesianismo, o fundamento de todo o conhecimento sobre a realidade encontra-se no intelecto. O sujeito chega ao conhecimento por meio de uma faculdade que lhe é própria, o pensamento fundado na razão. É próprio da razão não apenas fazer aceder o conhecimento, mas também impedir que fiquemos à mercê dos impulsos e das paixões que se mostram danosos à nossa existência (HESSEN, 2003).

O sujeito cartesiano apresenta-se, sobretudo, como um ser dotado de consciência e razão, instrumentos que lhe conferem a capacidade de conhecer o mundo e a si mesmo. Sua existência é deduzida do fato de ele pensar e constituir as bases de todo conhecimento possível. A subjetividade consciente realiza-se como atividade do entendimento e confere ao homem a capacidade de conhecer a si mesmo e as coisas que o circundam (HESSEN, 2003).

Kant (1724-1804), ao indagar sobre a natureza de nosso conhecimento, concedeu à razão o papel de juiz sobre o que podemos ou não conhecer, traçando assim os limites de nosso pensamento. Para o filósofo de Königsberg, nossa consciência só lida com fenômenos, já que a realidade não é externa ao indivíduo, mas produto de sua capacidade de pensar. Somos nós que, por meio de certas faculdades a priori, estabelecidas independentes da experiência, organizamos e damos sentido à realidade. Em consequência disso, na teoria kantiana a razão torna-se o núcleo do sujeito moderno (HESSEN, 2003). 
Diante disso, importa observar que a noção de sujeito pleno, autoconsciente e autônomo posta em cena pela filosofia da consciência/sujeito é a base que sustenta a maioria das abordagens em ciências sociais e, consequentemente, em ciências da administração. Entretanto, a concepção de homem da modernidade foi posta em cheque a partir do século XIX pelos chamados filósofos da suspeita: Marx, Nietzsche e Freud, que mobilizaram respectivamente a materialidade da história, o devir, e o inconsciente para abalar as bases do pensamento moderno e sua ideia de homem (RICOEUR, 1977).

Se o questionamento da ideia de sujeito encontra solo fértil entre os filósofos da suspeita, não podemos deixar de falar do movimento que decretou a morte do sujeito, o estruturalismo. Para Merquior (1991), o estruturalismo foi uma corrente de pensamento na ala humanista que nasceu da linguística moderna, cujo auge deu-se na França, na década de 60. Em seu apogeu, as estrelas do estruturalismo francês foram LéviStrauss, Barthes, Foucault, Lacan e Althusser. Cabe observar aqui que esses pensadores foram rotulados de estruturalistas em razão da apropriação que fizeram da linguística saussuriana para formularem suas teses. O fato é que as abordagens desses intelectuais simbolizaram, para os jovens pensadores do começo da década de 1960, o elo perdido entre a linguística de Ferdinand Saussure e as críticas ao humanismo e à fenomenologia.

Contudo, conforme será visto, o movimento estruturalista sofreu uma crise interna com o questionamento de alguns de seus pressupostos, o que levou ao que se chamou de pós-estruturalismo, cuja principal tarefa era a reelaboração da noção de sujeito fora da conotação ontológica, implicando alternativa entre o sujeito da liberdade radical do humanismo filosófico ou a morte do sujeito do estruturalismo. Desse modo, em virtude dessa virada crítica do estruturalismo em pós-estruturalismo, alguns dos pensadores que foram rotulados de estruturalistas passaram a ser classificados de pós-estruturalistas. Assim, no âmbito desde ensaio, tanto Foucault quanto Lacan são vistos como pós-estruturalistas, embora nenhum deles tenha reconhecido este rótulo.

O estruturalismo, apesar dos pontos de contato entre as teorias dos seus fundadores, não é um movimento, nem mesmo uma escola; é no máximo, como nomeou Barthes, uma atividade. Dosse (2007, p. 12) compartilha da ideia de Foucault de que o estruturalismo "[...] não é um método novo, ele é a consciência despertada e inquieta do saber moderno", não sendo possível pensar o estruturalismo apenas como recurso metodológico a ser utilizado em tal ou qual pesquisa, ele é antes "[...] um movimento de pensamento, uma nova forma de relação com o mundo".

Dosse (2007) e Merquior (1991) concordam que o estruturalismo colocou-se, notadamente, contra o modo de pensar associado ao existencialismo sartriano. O estruturalismo se opunha à centralidade do sujeito defendida pelo existencialismo, uma versão contemporânea da filosofia do cogito de Descartes. Além disso, essa corrente, de acordo com Merquior, também fez oposição ao historicismo, crença na lógica da história e do progresso abarcado por uma história linear.

É comum, entre os críticos do pensamento estruturalista, a acusação de que este decretou a morte do sujeito. Sendo assim, por esse viés, o sujeito nada mais é do que um apêndice estrutural. Contudo, há que se lembrar que essa visão encontra algum fundamento quando se fala da abordagem althusseriana (FERRY e RENAULT, 1985) ou levi-straussiana (RICOUER, 1977). Entretanto o mesmo não se pode dizer a respeito das perspectivas teóricas de Foucault e Lacan, por exemplo. Aqui importa observar que, embora Foucault e Lacan sejam rotulados de estruturalistas, isso se deve ao contexto em que o movimento aconteceu. Colado à linguística estrutural, Foucault, assim como Lacan, rompe com o sujeito do cogito cartesiano para pôr em seu lugar o sujeito descentrado, desenvolvendo, para tanto, a noção de posições de sujeito. Isso porque, de acordo com o autor, um sujeito pode ocupar múltiplas posições no espaço social, tais como o de: mulher, negra, médica, operária, professora, homossexual, etc. Foucault estudou os modos de subjetivação relacionados aos temas do saber/poder e da verdade/sujeito.

Lacan, por sua vez, realiza uma operação inversa à de Ferdinand Saussure com relação ao sujeito. De acordo com Jorge (2011), Saussure, com base na arbitrariedade do signo, busca escapar de uma correspondência psicológica e, com isso, exclui o sujeito de sua teoria. Lacan, ao contrário, recorre ao mesmo processo 
exatamente para inserir a questão do sujeito em sua reflexão, desenvolvendo, assim, a noção de sujeito como falta-a-ser, como se verá adiante.

A crítica à ausência de sujeito perante as estruturas por parte dos intelectuais da Sorbonne e de estudantes do Maio de 68 contribuiu para abalar as bases do estruturalismo. Contudo, a decadência do estruturalismo propriamente dita é marcada pela crítica iniciada internamente por Jacques Derrida ao estruturalismo. Este estudioso elabora uma crítica ao logocentrismo e advoga por um "descentramento" da estrutura. No clássico ensaio A estrutura, o signo e o jogo no discurso das ciências humanas, Derrida (1978, p. 278) questionava a "estruturalidade da estrutura" ou a ideia de "centro", que, segundo ele operava um limite ao jogo da estrutura:

Toda a história do conceito de estrutura tem de ser pensada como uma série de substituições de centro para centro. O centro recebe, sucessiva e regularmente, formas ou nomes diferentes. A história da metafísica, como a história do Ocidente, seria a história dessas metáforas e dessas metonímias. A sua matriz seria a determinação do ser como presença em todos os sentidos desta palavra. Poder-se-ia mostrar que todos os nomes do fundamento, do princípio, ou do centro, sempre designaram o invariante de uma presença: eidos, arché, telos, essência, existência, substância, sujeito, aletheia, transcendentalidade, consciência, Deus, homem, etc.

Assim, para Derrida (1978), o "descentramento" da estrutura e do sujeito soberano pode ser encontrado na crítica nietzscheana da metafísica, especialmente na crítica dos conceitos de "ser" e de "verdade"; na crítica freudiana da autopresença, consciência e do sujeito e, mais radicalmente, na destruição heideggeriana da metafísica platônica. Derrida, seguindo Nietzsche, Heidegger e Saussure, questiona os pressupostos que governam o pensamento binário, demonstrando como as oposições binárias sustentam, sempre, uma hierarquia ou uma economia que opera pela subordinação de um dos termos da oposição binária ao outro (DOSSE, 2007; SCHRIFT, 1995).

Todos esses pensadores, inclusive Lacan - do qual, se tomará, aqui, a noção de sujeito -, enfatizam que o significado é uma construção ativa, radicalmente dependente do contexto. Questionam, portanto, a suposta universalidade das chamadas asserções de verdade. Assim, seguindo o pensamento nietzschiano, todos eles questionam o sujeito cartesiano autônomo, livre e autoconsciente, que é tradicionalmente visto como a fonte de todo o conhecimento.

A retomada da noção de sujeito, entre outros, foi o ponto de inflexão que fez emergir o chamado pensamento pós-estruturalista. O pós-estruturalismo é, por certo, uma tentativa de superação da ideia de sujeito pressuposta da modernidade no que diz respeito às suas dimensões de sujeito universal ou como indivíduo. Assim, a ideia que preenche parcialmente o significante "pós-estruturalismo" pretende sugerir o esgotamento do pensamento filosófico moderno, sobretudo, em relação a esse aspecto central, o sujeito.

Não obstante, juntamente com o questionamento do conceito de sujeito, o pós-estruturalismo busca romper com as falsas dicotomias sujeito/objeto, teoria/prática, estrutura/ação. Muitos dos pensadores críticos à filosofia da consciência/sujeito adotam como referencial filosófico o pensamento nietzschiano contra a racionalidade moderna. Há, entretanto, que se observar que não só os pensadores rotulados de pósestruturalistas (Foucault, Derrida, Deleuze, Lacan, etc.) lançaram-se na crítica ao sujeito da filosofia da consciência. Outros pensadores, como os frankfurtianos Adorno, Horkheimer, Benjamin, por exemplo, também se dedicaram a essa empreitada (GALLO, 2012).

Peters (2000) destaca que os pensadores do pós-estruturalismo, ao seguirem a crítica nietzscheana da metafísica ocidental, baseiam-se em uma noção de sujeito imerso em toda sua complexidade histórica e cultural. Emerge, então, daí, a ideia de um sujeito descentrado e dependente do sistema linguístico, um sujeito discursivamente constituído e posicionado, constituído pela interseção de forças libidinais e de práticas socioculturais (PETERS, 2000). 
Assim, a problemática do sujeito como o elo que liga as reflexões de todos os estruturalismos da década de 60 foi também uma preocupação foucaultiana, a ponto de Foucault, em uma entrevista a Dreyfus e Rabinow (2010, p. 273), mencionar que "[...] não é a questão do poder, mas sim o sujeito que constitui o tema principal de minhas pesquisas". Cabe destacar que, além de Lacan e Foucault, outros expoentes da segunda geração de pensadores do movimento pós-estruturalista, Júlia Kristeva, Alain Baudiou, Felix Guattari, Suely Rolnik, também se aventuraram pelas questões do sujeito.

\section{Psicanálise Lacaniana: Sujeito como Falta}

Nesse tópico se discorrerá sobre o sujeito lacaniano, cuja perspectiva teórica, como é sabido, é devedora dos trabalhos de Freud sobre o inconsciente. Segundo Cabas (2010), a questão do sujeito é transversal à doutrina analítica, embora Freud nunca tenha construído uma teoria ou filosofia sobre o tema. Ao elaborar seus trabalhos, Freud tomou de empréstimo as noções de sujeito presentes na filosofia de seu tempo, a exemplo da noção do Eu cartesiano e do si-mesmo das psicologias da época. E, como era típico de seu modus operandis, submeteu essas referências a um debate crítico e ao crivo de sua clínica. Esse movimento representou uma subversão da ideia de sujeito como idêntico a si mesmo, dominante até então (CABAS, 2010).

Assim, a noção de sujeito, pode-se dizer, é uma referência sempre presente na obra de Freud, porém de forma implícita. Cabas (2010) relata ainda que essa palavra, "sujeito", aparece duas vezes em toda a obra de Freud e sem valor de conceito. Foi Lacan que, em seu retorno a Freud, outorgou-se a tarefa de extrair essa referência e explicitá-la em seu ensino. Conforme Fink (1998), toda a obra de Lacan é um debate crítico sobre a noção de sujeito e sua formalização. Assim, muitos dos termos utilizados por Lacan para desenvolver sua teoria do sujeito advêm das descobertas freudianas, como "inconsciente", "desejo" e a "divisão do sujeito". Outros termos tais como "falta constitutiva" e "objeto a", "objeto causa do desejo" e "produto que resta da operação de divisão do sujeito" são termos lacaniano por excelência.

Desse modo, a conclusão que se impõe, segundo Cabas (2010, p. 29) "[...] é que enquanto o inconsciente é freudiano, o sujeito é lacaniano". Assim, é por desenvolver uma teoria do sujeito em seu projeto de retorno a Freud que se trabalha aqui com a ideia de sujeito em Lacan. Nesse sentido, somos aqui lacanianos e não freudianos! Tal afirmação é feita em referência a um dito de Lacan em sua única conferência na América Latina, em Caracas, em 1980: "[...] sejam vocês lacanianos se quiserem eu sou freudiano" (JORGE e FERREIRA, 2005, p. 10). Lacan (1998), no chamado discurso de Roma, começa a articular o inconsciente com a estrutura da linguagem, fato que se tornou possível em virtude de seu encontro com Lévi-Strauss, que lhe apresentou Roman Jacobson e a linguística estrutural saussuriana.

O signo linguístico saussuriano une não uma coisa e um nome, mas um conceito e uma imagem acústica. Assim, para Arrivé (1999), Saussure deixa bem clara sua rejeição ao modelo de uma língua que funciona como nomeadora das coisas, ou seja, aquela que associa as palavras a um referente. O signo linguístico é uma entidade psíquica de duas faces: conceito e imagem acústica. A imagem acústica é a impressão psíquica do som e, não, o som material como a nomenclatura poderia levar a crer, a qual Saussure substitui respectivamente por significado e significante, conforme o desenho abaixo (ARRIVÉ, 1999). 
Figura 1

Signo Saussuriano

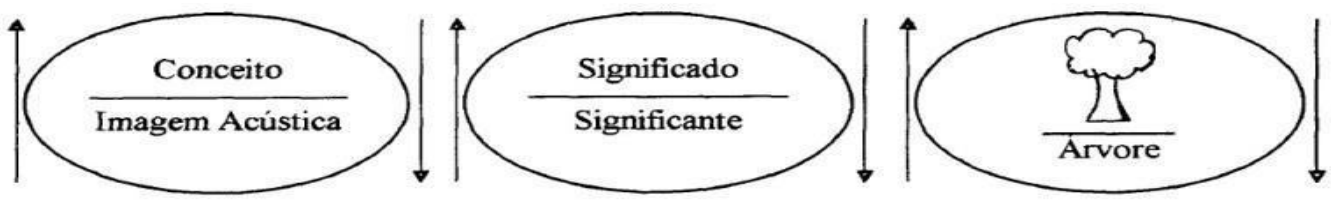

Fonte: Arrivé (1999, p. 57)

Conforme Arrivé (1999), na representação esquemática do signo saussuriano, é importante notar que a forma oval única que tem, de um lado, o significado, e, do outro, o significante, ratifica o caráter de se tratar de uma unidade linguística com as flechas, servindo para reafirmar exclusivamente que um lado remete necessariamente ao outro.

Em Saussure o signo é regido por um importante princípio, qual seja, o da arbitrariedade (ARRIVÉ, 1999). Aqui, cabe destacar, conforme Jorge (2011), a importância da noção de arbitrariedade do signo linguístico para Lacan. O autor observa que Lacan, no início de suas reflexões acerca da linguagem e do inconsciente, havia aceitado o princípio da arbitrariedade do signo tal qual defendido por Saussure. Porém, mais tarde irá introduzir em suas reflexões o conceito de contingência para substituí-lo. É interessante notar, nas palavras de Arrivé (1999, p. 77), que nesse ponto "[...] Lacan é mais saussuriano que o próprio Saussure, ao introduzir com a noção de contingência ou acaso, onde Saussure falava de uma decisão, implícita na noção de arbitrariedade".

A noção de valor do signo linguístico em Saussure remete à ideia de identidade e pressupõe que os significados (conceitos) são puramente diferenciais, definidos não positivamente por seu conteúdo, mas negativamente por suas relações com os outros termos da cadeia. Desse modo, a característica mais exata do conceito é ser o que os outros não são (ARRIVÉ, 1999). Além disso, conforme destaca Jorge (2011), Saussure, ao trabalhar com a produção de sentido no quadro de uma teoria do valor, solapou a aporia filosófica do referente, fato que interessou Lacan, para quem a produção de sentido é absolutamente independente do referente, o que confere à abordagem lacaniana a primazia do significante frente ao significado.

Desse modo, Lacan, no texto A instância da letra no inconsciente ou a razão desde Freud, apresenta a máxima "[...] o inconsciente é estruturado como uma linguagem", conferindo, por meio desse discurso, primazia ao simbólico. Para tanto, Lacan toma de Saussure seu esquema do signo linguístico, fazendo, porém, uma torção, retificando o paralelismo entre significante e significado, deixando em seu lugar uma função ativa do significante na determinação do significado (LACAN, 1998, p.496).

Assim, conforme Arrivé (1999), Lacan lança mão do significante para recuperar o valor da palavra, conferindo ênfase à fala, em oposição a Saussure, cuja estrela principal de suas teses é a língua. Assim, para fazer valer a dimensão inconsciente da ação do sujeito, Lacan precisou adaptar a relação entre significante e significado proposta na linguística saussuriana.

De acordo com Jorge (2011), a torção realizada por Lacan sobre o signo linguístico é importante e merece uma análise detalhada. Para esse autor, Lacan introduz alterações essenciais no algoritmo saussuriano, tais como: a) a exclusão do círculo que designa a unidade do signo, bem como a eliminação das flechas que indicam a relação recíproca entre significante e significado; b) a posição do significante é invertida e ele passa a ser representado pelo S maiúsculo acima da linha de separação; c) a linha que em Saussure designava a relação entre significante e significado ganha, em Lacan, o estatuto de uma barra de separação resistente à significação e constitui uma função de corte do discurso; d) o significado desliza sob o significante e produz, 
de tempo em tempo, um ponto de basta, em torno do qual se exerce toda a análise concreta do discurso (JORGE, 2011).

A primazia do significante em Lacan (1998) sustenta seu famoso aforismo: “[...] o sujeito representa um significante para outro significante" (LACAN, 1998, p. 508). Aqui é interessante pontuar que se Saussure, com base na arbitrariedade do signo, busca escapar de uma correspondência psicológica e, com isso, exclui o sujeito de sua teoria, Lacan, ao contrário, recorre ao mesmo processo exatamente para inserir a questão do sujeito em sua reflexão (JORGE, 2011).

Para tanto, Lacan (1998) trabalha a noção da falta na cadeia significante e, com base na concepção saussuriana de língua como sistema de valores diferenciais, reelabora a noção de sujeito fora da conotação ontológica que implica a alternativa entre o sujeito da liberdade radical do humanismo filosófico ou a morte do sujeito do estruturalismo.

De tal forma, importa salientar que, para Lacan (1998), a produtividade do significante verifica-se no erro, no equívoco, no vacilo da fala, na pluralidade de sentido, uma vez que permitem a passagem do inconsciente ao discurso. Assim, se é a estrutura da linguagem que se encontra no inconsciente, a primazia do significante sobre o significado revela o fato de que, no inconsciente, o significado é abolido; por isso, o significante só pode ser o que representa o sujeito para outro significante (LACAN, 1998).

Para Lacan (1998), os significantes apresentam-se na linha do tempo, numa sucessão diacrônica. Essa estrutura de cadeia do significante envolve uma dimensão temporal que vai da antecipação significante à retroação do significado, fazendo emergir uma significação. O significado, sendo efeito do significante, aparece retroativamente nos pontos de basta da cadeia significante ou, para falar em termos lacanianos, nesse momento se articula o ponto de estofo, pelo qual o significante detém o deslizamento indefinido da significação.

Desse modo, Lacan (1998) observa que é a estrutura da linguagem que a experiência psicanalítica descobre no inconsciente, consubstanciada, sobretudo, em uma instância primordial, a letra. Essa assertiva pretende afastar toda a ideia segundo a qual o inconsciente é apenas a sede dos instintos. Por letra, Lacan (1998) designa o suporte material que o discurso toma emprestado da linguagem, essa estrutura que pré-existe ao sujeito e o ultrapassa em sua finitude.

Com o objetivo de emprestar ares de ciência à psicanálise, Lacan se inspira notadamente nos trabalhos de Saussure, Jacobson e Lévi-Strauss em sua releitura de Freud (DOSSE, 2007). De Saussure, trabalha com a noção de arbitrariedade do signo e do seu valor diferencial, operando uma subversão no signo linguístico saussuriano ao conferir primazia ao significante, já que este agora tem outro valor que não se limita a suportar um significado, mas, sim, em fazer "[...] uma barreira resistente a toda significação" (LACAN, 1998, p. 500).

De Jacobson, Lacan toma emprestadas duas figuras de linguagem, a metáfora e a metonímia, como processos de funcionamento do inconsciente para explicar o desenvolvimento do discurso. Nesse caso, segundo Dosse (2007), a metáfora refere-se à condensação em Freud e a metonímia ao deslocamento. A metáfora consiste na substituição de significantes, fato que revela a autonomia do significante frente ao significado. A metonímia consiste em uma transferência de denominação que pode apresentar-se de diversas formas, em que toma o abstrato pelo concreto. Dosse (2007) destaca que Lacan sugere ao analista que tome o paciente à letra, abrindo mão de toda a hermenêutica. Isso porque a literalidade da fala apresenta em si mesma a cadeia significante, que é a trama do inconsciente.

Lévi-Strauss exerceu grande influência sobre Lacan. O deslocamento que o antropólogo logrou realizar em sua disciplina, da ênfase biológica para a cultural, privilegiando o modelo linguístico, é semelhante à realização de Lacan na psicanálise em sua busca pela desbiolologização do discurso freudiano. Com isso, a obra As estruturas elementares do parentesco, de Lévi-Strauss, serviu de leme para Lacan, que em seu 
discurso de Roma observou que a lei do incesto é aquela que regula a aliança entre os homens e sobrepõe o reino da cultura ao reino da natureza, não sendo nada além de uma ordem de linguagem (DOSSE, 2007).

O significante, para Lacan (1998), tem autonomia perante o significado, possuindo sentido somente quando articulado a outros significantes, e só pode operar por estar presente no sujeito. O sujeito, portanto, “[...] representa um significante para outro significante" e, dessa forma, está preso a uma estrutura que é capaz de emergir pela linguagem (LACAN, 1998, p. 508). O sujeito lacaniano é um efeito do significante, isso implica dizer que o sujeito não cria seu discurso, mas é causado por ele e só pode manifestar-se porque encontra na linguagem um substrato que o cria e permite seu advento. O sujeito precisa da palavra para existir e para dizer-se (LACAN, 1998).

O sujeito do inconsciente foi formulado por Lacan como um lugar, uma função, que, ao se revelar, enuncia um desejo desconhecido. O sujeito do inconsciente resulta do funcionamento e da incidência de discursos sociais e históricos sobre o corpo do ser vivente (bebê). Esses discursos são sustentados pelo Outro e organizados por referências pautadas pelo desejo. O Outro é propriamente a estrutura da qual a criança pequena deverá extrair a argamassa e os tijolos com os quais construirá a sua subjetividade (KUPFER, 2010).

Assim, para que se constitua esse sujeito, um bebê receberá dos pais inscrições psíquicas. Essas inscrições presidirão a uma longa e indefinida série de novas inscrições, desdobrando-se no tempo, em conexão com a primeira. Tais marcas manifestam-se vez por outra nas fraturas dos enunciados. O sujeito é a emergência dessas marcas postas em linguagem. Pode revelar-se em um lapso, mas também em uma inflexão da voz, em uma hesitação, em uma palavra sempre repetida (KUPFER, 2010).

As primeiras inscrições, observa Kupfer (2010), são marcas informes e precisam da palavra, do sonho, do rébus, da letra, enfim, de qualquer veículo no qual possa "pegar carona" para se fazer dizer, não somente no sentido de encontrar uma palavra, mas no sentido de encontrar uma forma para poder existir.

\section{O Homem nos Estudos Organizacionais}

Ainda que na filosofia antiga alguns filósofos demonstrassem interesse pelo homem como a medida de todas as coisas (CHAUÍ, 2010), a maioria deles defendia a natureza, os mitos, os deuses como o centro das explicações sobre o universo. O homem como objeto de pesquisa e o fundamento pelo qual o mundo passou a ser explicado é algo recente na história do pensamento ocidental (FOUCAULT, 1999). Conforme argumentamos anteriormente, para Foucault (1999) o homem surge no fim do século XVIII como um fenômeno da linguagem:

[...] é uma criatura muito recente que a demiurgia do saber fabricou com suas mãos há menos de 200 anos: mas ele envelheceu tão depressa que facilmente se imaginou que ele espera na sombra, durante milênios, o momento de iluminação em que seria enfim conhecido. (FOUCAULT, 1999, p. 425).

Assim, segundo Foucault (1999), é do pensamento de Kant em fins do século XVIII que o homem emerge como objeto de pesquisa, sendo a partir desse momento um duplo, qual seja, sujeito e objeto. $\mathrm{O}$ homem, enquanto objeto e sujeito de conhecimento é uma invenção recente do pensamento moderno, fruto, sobretudo, de uma linguagem que o separa do resto dos seres terrestres, além de o preceder e o ultrapassar em sua finitude.

Contudo, alguns estudiosos do tema (DOSSE, 2007; HALL, 2006; MERQUIOR, 1991) defendem que a concepção do homem moderno emerge com o humanismo renascentista do século XVI, mais precisamente a partir do pensamento de René Descartes (1596-1650) e a filosofia do cogito. A partir daí, grande parte da 
história da filosofia ocidental consiste de refinamentos dessa concepção do homem. Descartes recupera o pensamento dual, que desde Platão ocupa um lugar central na história do pensamento ocidental, e defende a existência de duas substâncias distintas: corpo e mente. Para ele, os fenômenos devem ser explicados por uma redução aos seus elementos essenciais: foi assim procedendo que ele colocou o sujeito do cogito no centro do conhecimento (HALL, 2006).

Essa visão racionalista do homem influenciou sobremaneira a teoria organizacional na sua versão funcionalista como pôde atestar Ramos em suas reflexões sobre as ciências da administração. Segundo Ramos (1984), a história dos estudos em administração foi marcada por teóricos que empreenderam abordagens acríticas a respeito da ideia de homem. Tal afirmação encontra respaldo nos modelos de homem surgidos das abordagens teóricas da teoria administrativa, tais como o homem operacional da administração clássica e o homem reativo, corolário do homem ajustado ao sistema, como o ápice dos estudos de Elton Mayo (RAMOS, 1984).

Assim, para Ramos (1984), as características psicológicas imputadas ao homem operacional e reativo pela teoria dominante em organizações implicam algumas consequências redutoras sobre o modelo de organização imposto. Isso fica evidente nas características dos modelos dominantes de gestão, apresentadas pelo autor, tais como: a) um método autoritário de alocação de recursos; b) uma concepção de treinamento como uma técnica destinada a ajustar o indivíduo aos imperativos da maximização; c) visão de que o homem é calculista, motivado por recompensas materiais e econômicas; d) a crença de que a administração e a teoria administrativa são imparciais e neutras; e) a ideia de que o trabalho é essencialmente um adiamento da satisfação (RAMOS, 1984).

Ramos (1984), em suas análises sobre a teoria da administração, no início da década de 1980, lança uma questão: a prática da administração avançou para além desse ponto? E, ele mesmo, nos fornece a resposta: não! E completa mencionando que os modelos operacional e reativo ainda continuam a influenciar em larga escala os sistemas sociais e organizacionais. Embora, nos meios acadêmicos, estes modelos sejam criticados, não há indícios de que apareceram ainda alternativas de ampla aceitação para substituí-los.

As alternativas epistemológicas ao homem economicus e suas versões mais sofisticadas, sociologicus e complexus, consubstanciadas na ideia de homem organizacional, emergiram notadamente com a introdução de novas abordagens teóricas ao campo dos Estudos Organizacionais a partir, sobretudo, da década de 80 (BRONZO e GARCIA, 2000; CLEGG e HARDY, 2001).

Isso fica evidente nos dizeres de Clegg e Hardy (2001) quando afirmam que, durante as últimas décadas, os estudos organizacionais vêm sofrendo mudanças surpreendentes. De maneira geral, o campo dos Estudos Organizacionais, desde seus primórdios no início do século $\mathrm{XX}$, caracteriza-se pelo predomínio das abordagens positivistas, cuja ideia subjacente de homem relaciona-se àquelas da filosofia da consciência que propõe um homem racional e autônomo. A contestação dessa hegemonia passa a ocorrer, de forma mais sistemática, a partir da década de 70 (MARDSEN e TOWNLEY, 2001) e estimula o aparecimento de novas posições epistemológicas em estudos organizacionais, para além do positivismo.

Assim, nos últimos 40 anos, por meio dessas novas abordagens tem-se tentado reestabelecer o que o positivismo removeu dos estudos organizacionais, a dimensão humana que escapa ao cálculo: os afetos. Uma evidência disso é a emergência dos estudos críticos em administração. As reflexões sobre o que são os estudos críticos, bem como em que se baseiam suas premissas já foram amplamente discutidos em nossa área (ALCADIPANI e TURETA, 2008; FARIA, 2009; MISOCZKY e ANDRADE, 2005; PAULA, MARANHAO e BARROS, 2009), cujas correntes de pensamento incluem, principalmente, o marxismo, a teoria crítica, o pós-estruturalismo e a psicanálise.

Sobre a abordagem crítica e a ideia de homem a ela subjacente, Souza, Souza e Silva (2013) observam que essa perspectiva se opõe à visão de homem defendida pelos clássicos da administração, bem como às formas de controle que subjugam os trabalhadores. Assim, a teoria crítica busca a emancipação do homem de tais práticas administrativas na medida em que utiliza um conceito de homem ligado fortemente às teorias 
neomarxistas defendidas pelos diversos autores da Escola de Frankfurt. Entretanto, Souza, Souza e Silva (2013) destacam que, apesar de seu posicionamento oposto, tanto as teorias organizacionais funcionalistas como as abordagens críticas, descritas pelos autores citados, possuem em comum uma ideia de homem próxima à da concepção contida na modernidade, qual seja, a crença na existência de uma essência humana.

\section{Problemática do Sujeito: Estudos Organizacionais e o Sujeito Lacaniano}

Como se pode observar desde Ramos (1984) e sua crítica à teoria da administração e ao reducionismo psicológico que confere ao homem, a teoria e prática organizacionais pouco acrescentaram a uma reflexão mais aprofundada do homem e, por consequência, da teoria organizacional. De maneira geral, pode-se dizer que as perspectivas teóricas tradicionais possuem uma visão de homem ligada ao racionalismo moderno e, com base nesse entendimento, definem tecnologias de gestão para controlá-los. Seja como homem economicus ou complexus, o homem organizacional é visto como possuidor de uma essência, uma origem. Assim, depreende-se que nas abordagens tradicionais em organizações buscou-se entender a essência humana com intuito de captar sua subjetividade a favor do interesse organizacional (SOUZA, SOUZA e SILVA, 2013).

Argumenta-se que essa visão de sujeito fica evidente na crítica guerreirista dos modelos de homem e nas reflexões realizadas por outros pesquisadores organizacionais notadamente no Brasil, como Prestes Motta, José H. Faria, Maurício Serva, Fernando Tenório (PAULA, 2008). As abordagens tradicionais em administração promovem um entendimento reducionista do homem, deslocado da noção primordial que o constitui enquanto sujeito, qual seja, a noção de inconsciente.

A descoberta do inconsciente foi um divisor de águas nas discussões sobre subjetividade. Depois de Freud, não se pode mais desconsiderar a dimensão dos afetos nas relações sociais. Com Freud compreende-se que a razão, desfigurada na modernidade como racionalidade técnica, não é mais que a ponta do iceberg na subjetividade humana. A brilhante descoberta freudiana é comparável em grandeza com as descobertas de Copérnico e de Darwin, para os quais, respectivamente, a terra não é o centro do universo e o homem descende dos primatas. Com a descoberta do inconsciente, Freud imprime à modernidade sua terceira ferida narcísica, a de que o homem (sujeito/eu) não é o senhor em sua própria casa.

Das novas abordagens teóricas evidenciadas pelos estudiosos críticos das organizações, a que nos interessa aqui é a psicanálise, sobretudo, lacaniana. Guimarães e Filho (2012) observam que, apesar de uma presença significativa da psicanálise nas discussões das ciências humanas, essa participação nos estudos organizacionais é muito recente.

Os autores mencionam alguns estudiosos citados por Freitas (2007) que se baseiam na psicanálise para fazer reflexões sobre seus objetos, a exemplo de Enriquez, com os conceitos de doenças e idealização; de Jean F. Chanlat, com as dimensões esquecidas do indivíduo; de Soares e Goulart, com os estudos sobre narcisismo; de José H. Faria, e seus estudos sobre poder e subjetividade; de Fernando P. Motta e Maria Ester de Freitas, e a vida psíquica nas organizações; de Ana Paula Paes de Paula, com crítica e psicanálise; de Anderson Sant'Anna com discussões sobre indivíduo, trabalho e organizações (GUIMARÃES e FILHO, 2012).

Corrobora-se a observação de Guimarães e Filho (2012) de que a psicanálise vem efetivamente contribuir para as ciências da administração por colocar em evidência uma dimensão esquecida, os afetos inconscientes. O inconsciente como o lugar do desejo, das pulsões e dos conflitos identitários foge de qualquer previsão, temporalização e da lógica social imposta pela racionalidade moderna social e organizacional.

Ora, o sujeito da psicanálise lacaniana, causado pelo Outro (ordem simbólica) como um ser em falta, rompe com os falsos dualismos (sujeito/objeto, estrutura/ação), além de evidenciar a relação estruturada/estruturante entre o sujeito e a estrutura. Stavrakakis (2007) afirma que diversos estudiosos das ciências sociais recorrem 
a Lacan para refletir sobre a questão do sujeito como meio de recuperar as discussões sobre a agência e as múltiplas possibilidades de novas sociabilidades. Desse modo, a noção de sujeito em Lacan é ponto de partida de muitos estudos políticos e passa a ser aqui também um conceito importante para pensar o sujeito no âmbito das ciências sociais em geral e da teoria das organizações em particular.

Outro fator de relevo para uma apropriação da noção de sujeito em Lacan na área de organizações é o consenso, entre muitos intelectuais que viveram os acontecimentos dos anos de 1960 (DOSSE, 2007), em relação a Lacan como o pensador que mais longe foi na discussão sobre o sujeito e desenvolveu uma abordagem que rompe com o dualismo estrutura/agência, na medida em que o sujeito lacaniano só se constitui enquanto tal na sua relação estruturada e estruturante com a ordem simbólica.

Assim, por meio da psicanálise lacaniana, é possível observar que o sujeito não é nenhum ser metafísico ou mitológico, à maneira de um herói, como muitas vezes nos faz crer o pensamento filosófico tradicional. Disso, depreende-se que o processo de causação do sujeito impõe-se a todos nós de forma estruturada e estruturante com o mundo que nos cerca.

A reflexão sobre o sujeito não se dá sem consequências para os estudos organizacionais, já que estudar o sujeito com base na ideia de uma identidade construída nos embates cotidianos das vidas dos sujeitos proporcionaria implicações na maneira como os pesquisadores organizacionais realizam suas pesquisas e na forma como ocorre o processo de formação do administrador (HARDY e CLEGG, 2001; PAULA, 2012). Hardy e Clegg (2001) declaram que, ao olhar o sujeito como constituído por eventos além de qualquer controle imediato, a distância entre pesquisador e pesquisado diminui, o que implica uma revisão nas metodologias de pesquisa utilizadas pela área que tem por bases epistemológicas a noção de sujeito essencializado, como é o caso das metodologias positivistas e interpretacionistas, incluindo metodologias etnográficas e fenomenológicas.

Ora, refletir sobre novas metodologias de pesquisa com base, por exemplo, no sujeito lacaniano, coloca o importante desafio, qual seja, o de trabalhar com a ideia de contingência e acaso. Isto porque o sujeito à maneira de Lacan (1998) é um sujeito dividido entre o Eu (consciente) e o Inconsciente, o que significa dizer que nem todas as suas ações são planejadas ou calculadas como quer a razão indolente. Desse modo, as práticas organizacionais, assim como o sujeito não podem ser apreendidos e elucidados completamente, sempre há um resto não simbolizável (que não se inscreve no discurso), que não se alcança nem com a mais rigorosa análise empírica.

Diante do que foi dito acima, compartilha-se a visão de Paula (2013) sobre a importância de opções metodológicas que privilegiem a capacidade de ação dos sujeitos de modo a romper com a falsa dicotomia teoria/prática e contribuir para a mudança social por meio de uma práxis libertadora (projeto político).

Todo projeto político contempla uma dimensão ético-normativa sobre a qual os pesquisadores críticos da área de organizações podem se posicionar e se responsabilizar. Assim, faz-se coro a alguns estudiosos da área, afirmando-se que se impõe uma nova visão de sujeito que leve em conta os afetos inconscientes. Ora, pois, corrobora-se Paula (2012), que mobiliza o pensamento freudiano para dizer que educar (pode-se pensar aqui em pesquisar, ensinar, administrar), ao lado da psicanálise e da arte de governar, está entre as profissões impossíveis, uma vez que não se submete o inconsciente (FREUD, 1980).

A mesma reflexão vale para as abordagens organizacionais que desenvolvem ferramentas de gestão para controlar os corpos e mentes dos trabalhadores (FARIA, 2007): o inconsciente não se submete! Assim, levar em consideração o inconsciente e suas manifestações pode nos ajudar a compreender por que algumas propostas de mudança social e organizacional ou de movimentos sociais e projetos emancipatórios falham ou não mobilizam sujeitos para suas causas. Com base nessa compreensão, em uma dimensão ontológica, é possível, no plano ôntico, propor alternativas ao que está posto pela razão indolente e, nesse sentido, engrossar o brado freiriano dos atos de denúncia e anúncio. 


\section{(In)conclusões}

Neste ensaio o objetivo foi discutir a problemática do sujeito na tradição do pensamento filosófico moderno que influenciou sobremaneira o campo das ciências sociais e seus subcampos, tais como o da ciência da administração. Dito isso, cabe ressaltar que este ensaio não se pretendeu exaustivo no sentido de realizar uma busca completa sobre toda a produção científica em administração que trate dessa problemática. Sabe-se que o questionamento dessa ideia de sujeito não é nova na área de Estudos Organizacionais, bem como a própria base epistemológica que lhe fundamenta (o pós-estruturalismo, a psicanálise) e na qual podemos encontrar uma série de trabalhos (ALCADIPANI e TURETA, 2008; 2009; GUIMARÃES e FILHO, 2012; PAES e DELLAGNELO, 2013; PAULA, 2012; 2013; SOUZA, SOUZA e SILVA, 2013), com interessantes discussões sobre a epistemologia pós-estruturalista e psicanalítica.

Assim, em consonância com os atos de denúncia e anúncio dos pensadores críticos em administração, neste ensaio se pretendeu mostrar que o sujeito visto com a lente epistemológica da psicanálise lacaniana não é o sujeito racional e pleno das teorias tradicionais. O sujeito da filosofia da consciência, fruto de uma construção discursiva cujos contornos conceituais são definidos a priori, serve a interesses diversos na luta para impor uma visão de mundo nos diversos campos do saber, inclusive, no da administração.

A esse sujeito essencialista se opõe a psicanálise lacaniana. Desse modo, os apontamentos de Nietzsche e, sobretudo, da epistemologia lacaniana desconstroem os traços essencialistas do sujeito cartesiano para pôr em seu lugar um homem que se constitui na e pela linguagem, sendo fruto, portanto, de forças socioculturais e libidinais que o tornam um ser faltante. Essa qualidade ontológica do ser não permite seu fechamento numa identidade fixa, dado que em Lacan o sujeito é sempre falta-a-ser, uma vez que não há na cultura um significante capaz de representar completamente o sujeito, bem como não há um objeto capaz de completar o desejo do sujeito e tamponar sua falta-em-ser.

Isto posto, tem-se que o conceito de sujeito tal qual defendido pela psicanálise lacaniana lança luz aos processos psíquicos que nos constituem enquanto sujeitos por meio de uma falta estruturante. Esta falta constitutiva nos faz seres desejosos e alienados na linguagem. Essa dinâmica da constituição do sujeito o torna um ser dividido entre o ser (sujeito) e o sentido (Outro); na sua reunião, constitui-se uma zona de condensação que não provém propriamente de nenhum, mas que possui elementos de ambos: o não-sentido, domínio do inconsciente.

Portanto, de uma perspectiva psicanalítica, o sujeito é sempre um falta-a-ser, algo que não encontra uma definição pronta e acabada, um ser que sempre busca uma completude impossível. Desse modo, podemos inferir que nenhuma teoria seria capaz de dar conta desse ser e que as teorias administrativas dominantes reduzem sobremaneira o homem a um objeto que responde a estímulo e que possui uma razão que o faz um grande tomador de decisões. Essa ideia de homem obedece, para falar em termos foucaultinos, a uma vontade de poder que pretende criar corpos dóceis para a extração da mais valia nas organizações que se pretendem totais na modernidade.

Cabe ainda destacar que é, sobretudo, com o pensamento lacaniano que pensadores das teorias posfundacionalistas da sociedade, tais como Laclau e Mouffe (1985), buscaram resgatar a noção do sujeito, bem como as categorias epistemológicas da psicanálise para pensar uma teoria da subjetividade (STAVRAKAKIS, 2007) e refletir sobre o político e, portanto, sobre a ação que promove a mudança social. Esta reflexão pode ajudar a superar a visão de alguns autores organizacionais de que a perspectiva (pós)estruturalista enfraquece a mobilização política na medida em que relativiza o mundo social e fragmenta a noção de sujeito.

Assim, é por acreditar, como Paula (2012), Serva, Dias e Alperstedt (2010) e Ramos (1984), na necessidade de pensar novas categorias para a ciência da administração que se busca, aqui, na concepção lacaniana de sujeito, o vetor para desconstruir a ideia de homem subjacente à teoria organizacional tradicional. Tal empreendimento foi motivado pelo entendimento de que os momentos de liberdade existentes nas lacunas ou 
nos furos da estrutura são constitutivos de novas sociabilidades que o discurso hegemônico idolente insiste em ocultar (BOAVENTURA, 2002).

O pensamento hegemônico moderno, dito capitalista, busca preencher os buracos produzidos pelos discursos e cria com isso dispositivos disciplinares (FOUCAULT, 2004) para dar estabilidade ao caos constitutivo do social (LACLAU e MOUFFE, 1985; 1990). Ora, pois, se o discurso nunca é totalizante e se apresenta furado, são esses mesmos buracos, como linhas de fuga (DELEUZE e GUATTARI, 2007), que nos permitem resistir e construir novas sociabilidades.

\section{Referências}

ALCADIPANI, R.; TURETA, C. Pós-estruturalismo e análise das organizações: a contribuição da teoria ator-rede. In: ENEO, 2008, Belo Horizonte. Trabalhos Apresentados. Belo Horizonte, 2008.

ALCADIPANI, R.; TURETA, C. Perspectivas críticas no Brasil: entre a "verdadeira crítica" e o dia a dia. Cad. EBAPE.BR, v. 7, n. 3, p. 504-508, 2009.

ARRIVÉ, M. Linguagem e psicanálise, linguística e inconsciente: Freud, Saussure, Pichon, Lacan. Rio de Janeiro: Zahar, 1999.

BOURDIEU, Pierre. Razões Práticas. 11. ed. Campinas: Papirus, 2011.

GARCIA, F. C.; BRONZO, M. As bases epistemológicas do pensamento administrativo convencional e a crítica à teoria das organizações. In: Anais do I ENEO. Curitiba, 2000.

CABAS, A. G. O sujeito e a psicanálise de Freud a Lacan: da questão do sujeito ao sujeito em questão. Rio de Janeiro: Jorge Zahar Ed., 2010.

CHANLAT, J. F. O indivíduo na organização: dimensões esquecidas. v. I. São Paulo: Atlas, 2000.

CHAUÍ, M. de S. Convite à filosofia. 14. ed. São Paulo (SP): Ática, 2010.

CLEGG, S. R.; HARDY, C. Conclusão: representação. In: CLEGG, S. R.; HARDY, C.; NORD, W.R. Handbook de Estudos Organizacionais: reflexões e novas direções, v. 2. São Paulo: Atlas, 2001.

JORGE, M. A. Fundamentos da Psicanálise de Freud a Lacan. v. 1. As bases. 5. ed. Rio de Janeiro: Jorge Zahar Editor, 2011.

DELEUZE, G.; GUATTARI, F. Mil platôs: capitalismo e esquizofrenia. São Paulo: Ed. 34, 2007.

DERRIDA, J. Gramatologia. São Paulo: Perspectiva, 1978.

DOSSE, F. História do estruturalismo. Bauru (SP): EDUSC, 2007.

DREYFUS, H. L.; RABINOW, P. Michel Foucault: uma trajetória filosófica: para além do estruturalismo e da hermenêutica. Rio de Janeiro: Forense Universitária, 2010.

FARIA, J. H. Teoria crítica em estudos organizacionais no Brasil: o estado da arte. Cad. EBAPE. BR, v. 7, n. 3, p. 509-515, Rio de Janeiro, Set. 2009.

FARIA, J. H.; MENEGHETTI, F.K. Sequestro da subjetividade e novas formas de controle psicológico no trabalho: uma abordagem crítica ao modelo toyotista de produção. In: FARIA, J. H. (Org.). Análise crítica das teorias e práticas organizacionais. São Paulo: Atlas, 2007. 
FERRY, L.; RENAUT, A. Pensamento 68: ensaio sobre o anti-humanismo contemporâneo. São Paulo (SP): d. Ensaio, 1985.

FINK, B. Entre a linguagem e o gozo. Rio de Janeiro: Jorge Zahar Ed., 1998.

FOUCAULT, M. As palavras e as coisas: uma arqueologia das ciências humanas. São Paulo: Martins Fontes, 1999.

FOUCAULT, M. Vigiar e punir: nascimento da prisão. Petrópolis: Vozes, 2004.

FREITAS, M. E. Prefácio. In: GODOI, C. K. Psicanálise das organizações. Contribuições da teoria psicanalítica aos estudos organizacionais. Itajaí: Editora Univali, 2007.

FREUD, S. Análise terminável e interminável. Rio de Janeiro: Imago. v. 23, [1937], 1980.

GALLO, S. Anarquismo e educação: os desafios para uma pedagogia libertária hoje. Política e trabalho. Revista de Ciências Sociais, n. 36, p. 169-186, abril 2012.

GODOI, C. K. Psicanálise das organizações. Contribuições da teoria psicanalítica aos estudos organizacionais. Itajaí: Editora Univali, 2007.

GUIMARÃES, L. V. M.; FILHO, A. M. Epistemologia freudiana e Estudos Organizacionais: novas possibilidades para a pesquisa. In: ENEO, 2012, Curitiba, 2012.

HALL, S. A identidade cultural na pós-modernidade. 11. ed. Rio de Janeiro: DP\&A, 2006.

HARDY, C.; CLEG, S. Alguns ousam chamá-lo de poder. In: CLEG,S.; HARDY,C.; NORD,W. (Eds.). Handbok de estudo organizacionais. São Paulo: Atlas, 2001.

HESSEN, J. Teoria do conhecimento. São Paulo: Martins Fontes, 2003.

JORGE, M. A. C.; FERREIRA, N. P. Lacan, o grande freudiano. Rio de Janeiro: Jorge Zahar, 2005.

KUPFER, M. C. O Sujeito na Psicanálise e na Educação: bases para a educação terapêutica. Revista Educação \& Realidade, Porto Alegre, v. 35, n. 1, p. 265-281, jan./abr. 2010.

LACAN, J. Escritos. Rio de Janeiro (RJ): Zahar, 1998.

LACLAU, E.; MOUFFE, C. Hegemony and socialist strategy: towards a radical democratic politics. London, New York: Verso, 1985.

MACHADO, R. Foucault, a ciência e o saber. Rio de Janeiro: Jorge Zahar Ed., 2007.

MARSDEN, R.; TOWNLEY, B. Introdução: A coruja de Minerva: reflexões sobre a teoria na prática. In: CLEGG, S. R.; HARDY, C.; NORD, W. R. Handbook de Estudos Organizacionais: reflexões e novas direções. v. 2. São Paulo: Atlas, 2001.

MERQUIOR, J. G. De Praga a Paris: uma crítica do estruturalismo e do pensamento pós-estruturalista. Rio de Janeiro: Nova Fronteira, 1991.

MISOCZKY, M. C.; ANDRADE, J. A. Uma crítica à crítica domesticada nos Estudos_Organizacionais. Revista de Administração Contemporânea, v. 9, n. 1, p. 215-233, mar. 2005.

MOSÉ, V. Nietzsche e a grande política da linguagem. Rio de Janeiro: Civilização Brasileira, 2011.

MOTTA, F. C. P. Os pressupostos básicos de Schein e a fronteira entre a psicanálise e a cultura organizacional. In: MOTTA, F. C.; FREITAS, M. E. Vida Psíquica e Organização. Rio de Janeiro: FGV, 2000.

NIETZSCHE, F. A Gaia Ciência. São Paulo: Companhia das Letras, 1. ed. 2001. 
NIETZSCHE, F. Humano, demasiado humano: texto integral. São Paulo: Escala, 2006.

PAES, K. D.; DELlaGNElO, E. H. L. Sujeito Pleno, Morte do Sujeito ou Sujeito-falta-a-ser: A Problemática do Sujeito na Epistemologia Lacaniana e Sua Implicação Para os Estudos Organizacionais. In: ENCONTRO DA ASSOCIAÇÃO NACIONAL DE PÓS- GRADUAÇÃO EM ADMINISTRAÇÃO, 37., Rio de Janeiro, 2013.

PAULA, A. P. P. Teoria Crítica nas organizações. São Paulo: Thomson Learning, 2008.

PAULA, A. P. P. Estilhaços do Real: o ensino da administração em uma perspectiva benjaminiana. Curitiba: Juruá, 2012.

PAULA, A. P. P. Abordagem freudo-frankfurtiana, pesquisa-ação e socioanálise: uma proposta alternativa para os Estudos Organizacionais. Cad. EBAPE.BR, v. 11, n. 4, p. 543-555, dez. 2013.

PAULA, A. P. P.; MARANHAO, C. S.; BARROS, A. N. Pluralismo, pós-estruturalismo e "gerencialismo engajado": os limites do movimento critical management studies. Cad. EBAPE.BR, v. 7, n. 3, p. 393-404, 2009.

PECI, A. Estrutura e ação nas organizações: algumas perspectivas sociológicas. Revista de Administração de Empresas, v. 43, n. 1, p. 24-35, jan./mar. 2003.

PETERS, M. Pós-estruturalismo e filosofia da diferença. Belo Horizonte: Autêntica, 2000.

RAMOS, A. G. Modelos de Homem e Teoria Administrativa. Rev. Adm. Pública, v. 18, n. 2, p. 3-12, abr./jun. 1984.

RIAVIZ, V. N. Alienação e separação: a dupla causação do sujeito. Dissertação (mestrado). Centro de Filosofia e Ciências Humanas. Universidade Federal de Santa Catarina, 1998.

SANT'ANNA, A. S. Contemporaneidade e novas formas de relação sujeito-trabalho-organizações: o que teria a nos dizer a psicanálise. 2011. Monografia (Formação Psicanalítica) - Círculo Psicanalítico de Minas Gerais, Belo Horizonte.

SCHRIFT, A. D. Nietzsche french legacy: a genealogy of poststructuralism. New York: Routledge, 1995.

SANTOS, B. de S.. Para uma sociologia das ausências e uma sociologia das emergências. Revista Crítica de Ciências Sociais, n. 63, p. 237-280, 2002.

SERVA, M.; DIAS, T. ALPERSTEDT, G. O paradigma da complexidade e a teoria das organizações: uma reflexão epistemológica. Revista de Administração de Empresas, v. 50, n. 3, p. 276-287, 2010.

SOUZA, E. M; SOUZA, S. P.; SILVA, R. L. O pós-estruturalismo e os estudos críticos de gestão: da busca pela emancipação à constituição do sujeito. Revista de Administração Contemporânea, v. 17, n. 2, p. 198-217, MarçoAbril 2013.

STAVRAKAKIS, Y. Lacan y lo politico. Buenos Aires: Prometeo - UNLP, 2007.

VERGARA, S. C.; CALDAS, M. P. Paradigma Interpretativista: a busca da superação do objetivismo funcionalista nos anos 1980 e 1990. Revista de Administração de Empresas, v. 45, n. 4, p. 66-72, out./dez. 2005. 